\title{
Compensatory orthodontic treatment of Angle Class II malocclusion with posterior open bite
}

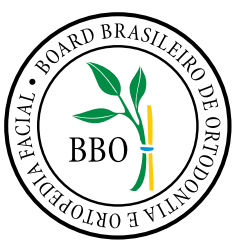

\author{
José Newton Torres ${ }^{1}$
}

The present case report addresses the treatment of an Angle Class II malocclusion in an adult female patient, long face pattern, with posterior open bite and dental arches extremely expanded, due to previous treatment. The patient and parents rejection to a treatment with orthognathic surgery led to orthodontic camouflage of the skeletal discrepancies. This clinical case was presented to the Brazilian Board of Orthodontics and Facial Orthopedics (BBO) as one of the requirements to become a BBO Diplomate.

Keywords: Angle Class II. Anterior open bite. Orthodontic camouflage.

O presente relato de caso aborda o tratamento de uma má oclusão de Classe II de Angle em paciente do sexo feminino, adulta, face longa, com mordida aberta posterior, e arcadas dentárias extremamente expandidas, decorrente de tratamento prévio. A não aceitação, por parte da paciente e de seus pais, de um tratamento envolvendo cirurgia ortognática levou à realização de camuflagem ortodôntica das discrepâncias esqueléticas. Esse caso clínico foi apresentado à Diretoria do Board Brasileiro de Ortodontia e Ortopedia Facial (BBO) como parte dos requisitos para obtenção do título de Diplomado pelo BBO.

Palavras-chave: Classe II de Angle. Mordida aberta anterior. Camuflagem ortodôntica.

\section{INTRODUCTION}

Female patient searched for treatment at the age of 18.7 months, with the chief complaint that, after 7 years with removable appliances, she was not satisfied with the final result and was not able to "chew food with posterior teeth", swallowing the food in big pieces. There was no relevant data in her medical history.

\section{DIAGNOSIS}

The patient presented a Class II skeletal pattern, characterized by mandibular deficiency, with $\mathrm{ANB}=6^{\circ}$ $\left(\mathrm{SNA}=82^{\circ}\right.$ and $\left.\mathrm{SNB}=76^{\circ}\right)(\mathrm{Tab} 1)$. The profile was

${ }^{1}$ Specialist in Orthodontics and Facial Orthopedics by the ACD/Campinas. Director of the Brazilian Association of Orthodontics and Facial Orthopedics (ABOR) and BBO Diplomate.

How to cite this article: Torres JN. Compensatory orthodontic treatment of Angle Class II malocclusion with posterior open bite. Dental Press J Orthod. 2013 Sept-Oct;18(5):140-6. convex, with obtuse nasolabial angle, nasal apex slightly to the right, long face pattern, absence of passive lip sealing, increased lower facial third and short neck-chin line (Fig 1). The intraoral exam detected an Angle Class II, division 1 malocclusion, expanded and asymmetric upper and lower arches, 6-mm overjet, posterior open bite, only with second molar occlusal contact and excessive wearing on the upper and lower molar cusps, due to an attempt of occlusal adjustment (Figs 1 and 2). The upper and lower incisors were protruded and with buccal tipping, with apical rounding of the upper incisor roots (Figs 3 to 5).

» The author reports no commercial, proprietary or financial interest in the products or companies described in this article.

" The patient displayed in this article previously approved the use of her facial and intraoral photographs.

Contact address: José Newton Torres

SCN Qd 2, bloco D, entrada A, sala 911 - Brasília / DF - Brazil

CEP: 70.712-903 - Email: torres.jn@terra.com.br 

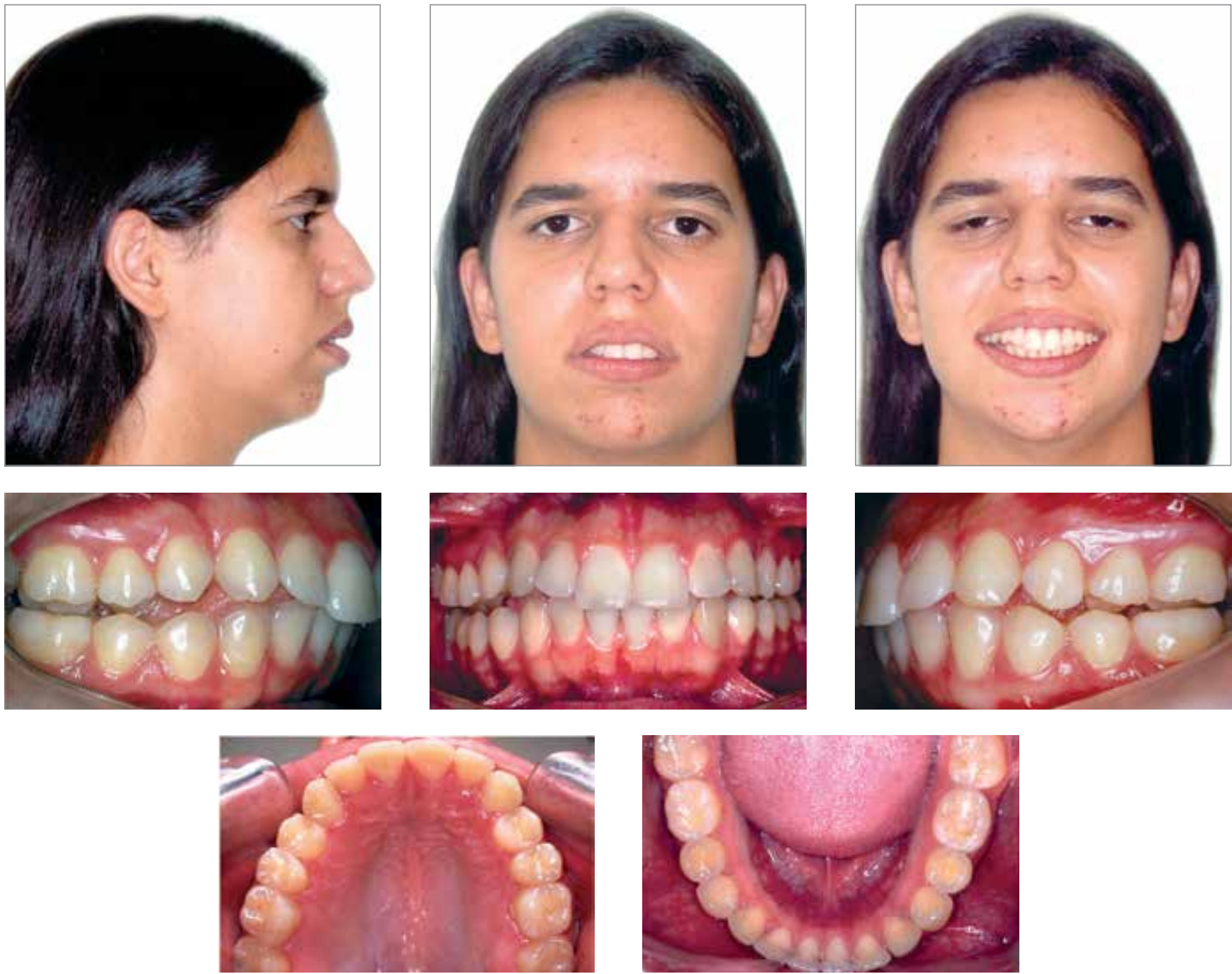

Figure 1 - Initial facial and intraoral photographs.
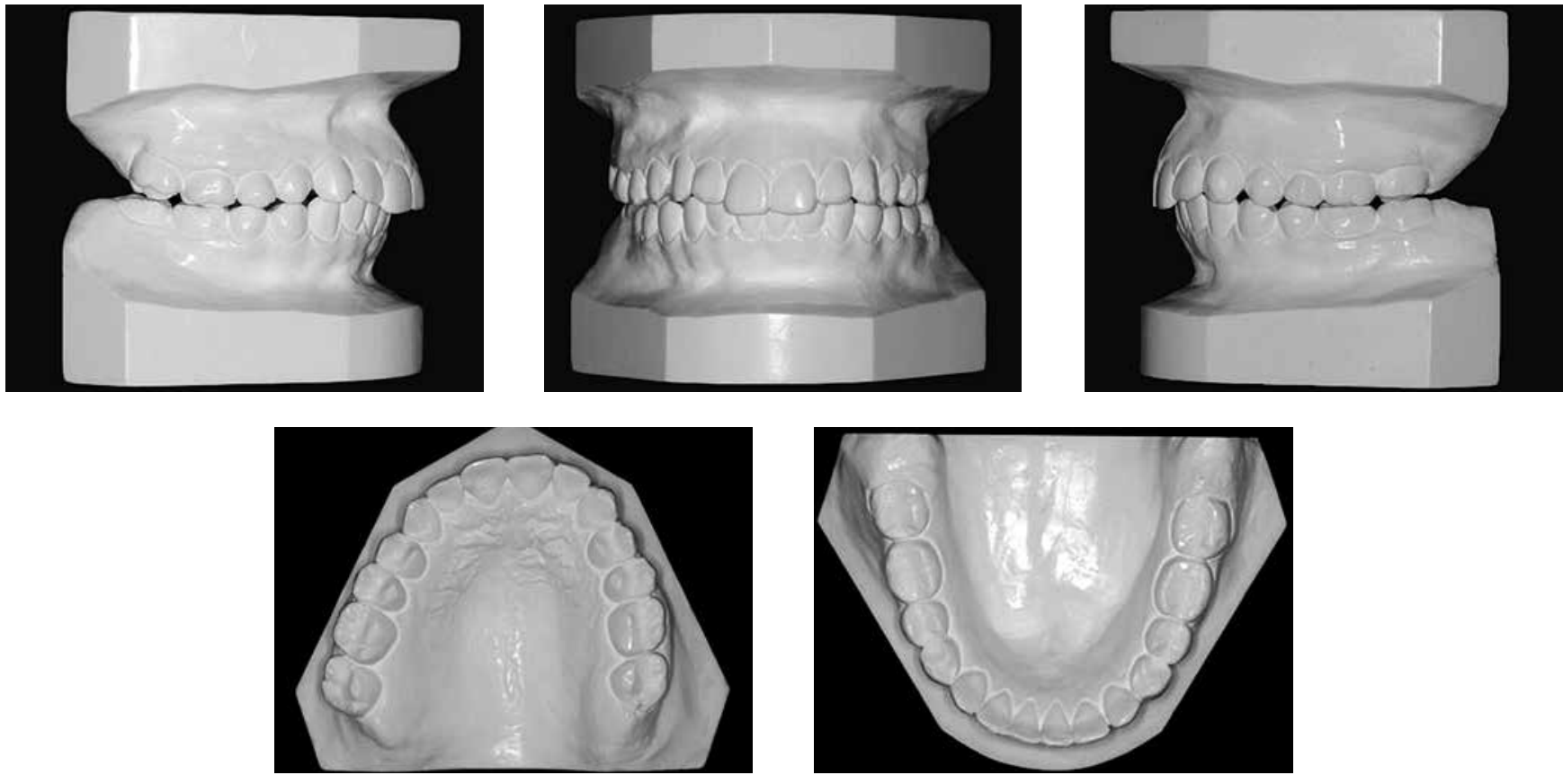

Figure 2 - Initial dental casts. 

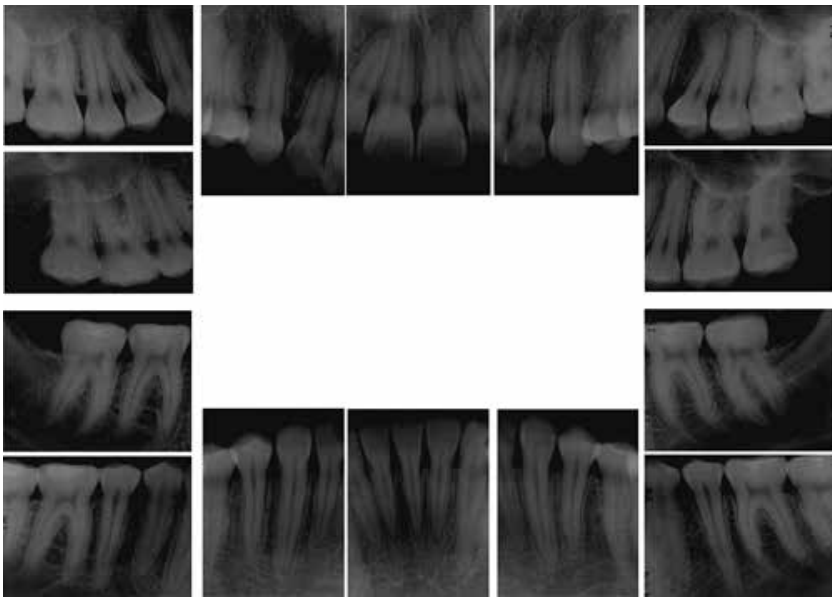

Figure 3 - Initial periapical radiographs.
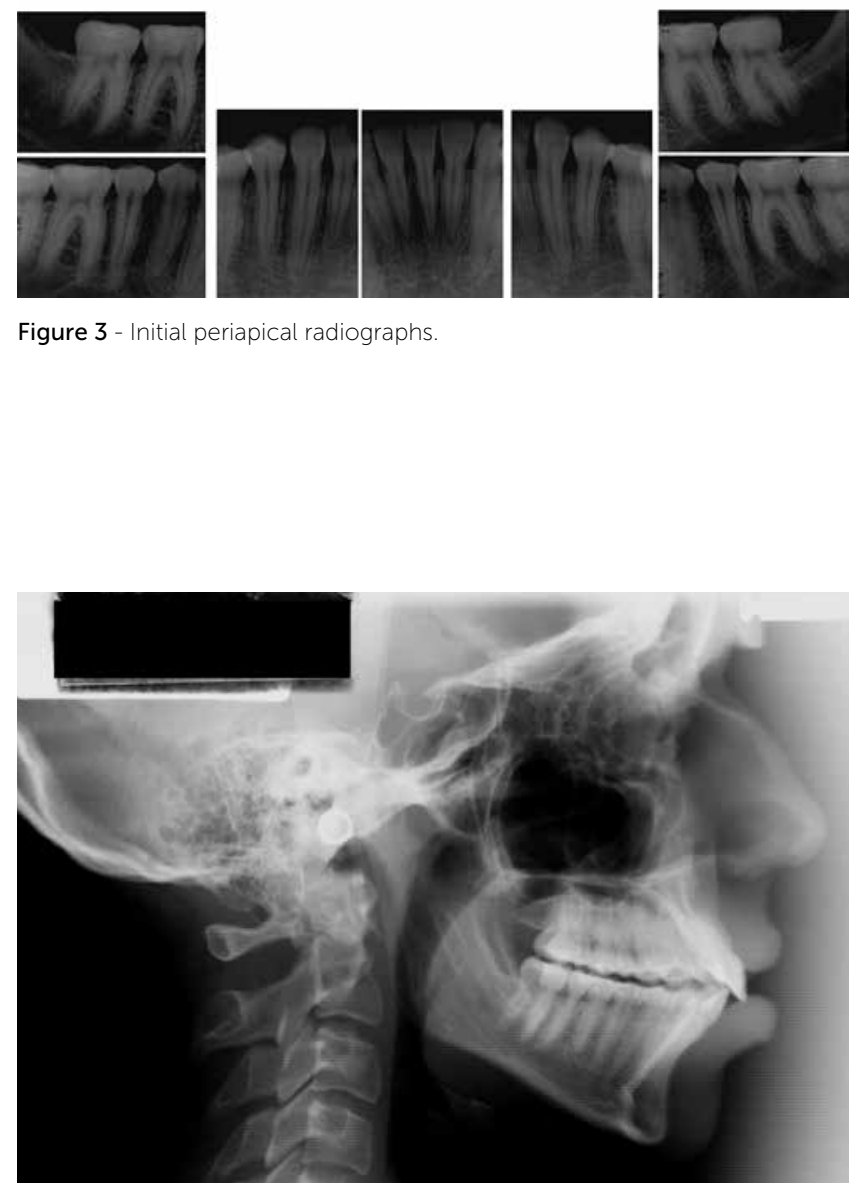

Figure 5 - Initial lateral cephalometric radiographs.

\section{TREATMENT PLAN}

The first treatment plan option presented to the parents and the patient was the surgical-orthodontic combined treatment, which was immediately refused. Thus, an alternative with orthodontic camouflage was presented, which consisted on the use of upper and lower fixed orthodontic appliances, and

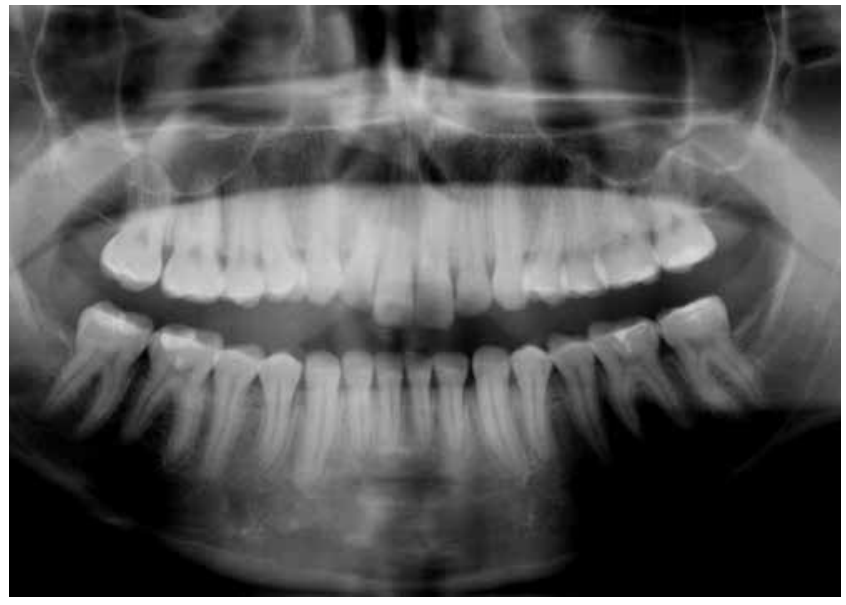

Figure 4 - Initial panoramic radiographs.

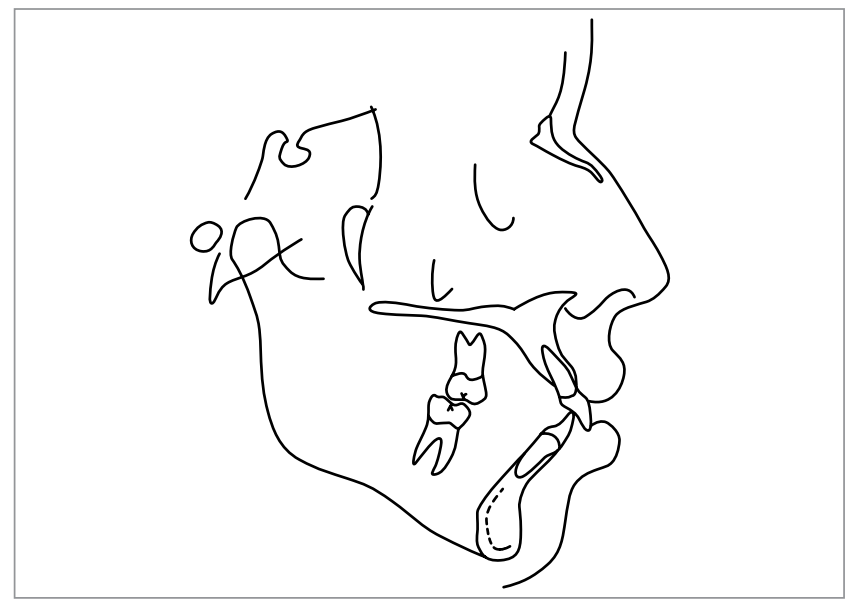

Figure 6 - Initial cephalometric tracing.

four premolars extraction. The spaces after extraction would be, then, used to correct the molar and canine relationships, and also the overjet, allowing occlusion of the anterior teeth. Contraction of the upper arch would be performed with the use of a removable palatal bar, with contracted archwires for both upper and lower dental arches. For finishing and intercus- 
pation braided archwires and intermaxillary elastics (5/16-in) would be used. The retention planned was a wraparound removable upper plate, and lingual canine-to-canine fixed retainer.

Thus, the treatment objectives were to reduce the SNA angle, by retracting the upper incisors, maintaining the maxilla and mandible in their vertical position, contracting upper and lower dental arches, correcting molar and canine relationship, the open bite, overbite and overjet, improving facial profile, if possible.

\section{TREATMENT PROGRESS}

The maxillary and mandibular first and second molars were banded and the other teeth were bonded. Straight-wire brackets (0.022-in x 0.028-in), Roth's prescription, were used. A contracted palatal bar was placed in the upper first molars and the extraction of upper first premolars was requested, followed by the extraction of lower second premolars. Alignment and leveling was started after extracting these teeth with 0.014-in, 0.016-in, 0.018-in NiTi archwires; in addition, Australian 0.020-in wire, 0.017 X 0.025-in $\mathrm{NiTi}$ and 0.019 X 0.025-in stainless steel (SS) archwires were used. Then, space closure was performed with the aid of $0.019 \times 0.025$-in SS archwires with prevalence of upper anterior teeth retraction, and anchorage loss of lower posterior teeth. After a few appointments, difficulty in moving teeth of the lower right side was observed. Thus, mini-implants placement in this region was performed for skeletal anchorage, until the total closure of spaces.

Intercuspation was performed as planned, using $0.021 \times 0.025$-in braided archwires and 5/16-in intermaxillary elastics (150 gf).

\section{RESULTS}

There was maintenance of the vertical position in both arches, with slight reduction of the SNA angle, which led to a reduction of the ANB angle (Table 1). The relationship for molars and canines in key of oc- clusion was obtained on both sides, closing of the posterior open bite, correction of overjet and contraction of upper and lower arches were also achieved (Figs 7 and 8). A decrease in upper and lower intermolar distance of $10 \mathrm{~mm}$ and $11 \mathrm{~mm}$, respectively, was observed, as well as a decrease of upper and lower intercanine distance of $3 \mathrm{~mm}$ in both arches. A slight increase of the nasolabial angle was observed, due to the retrusion of anterior upper teeth, with little alteration of the facial profile, keeping the absence of passive lip sealing, and hyperactive mentalis muscle.

A good root parallelism was obtained at the end of treatment, as observed in the panoramic radiograph (Fig 9). Periapical radiographs showed slight increase in the apical root remodeling of incisors (Fig 10).

On cephalometric superimpositions extrusion of first upper molar was observed, which was compensated by the mesial movement of the lower molar (Figs 13 and 14), contributing for the maintenance of the mandibular plane angle. The great reduction of the intermolar distance obtained was possible due to the mesial movement of these teeth, which came to occupy a narrower region on the basal bones. For retention a canine-tocanine fixed retainer was used on the lower arch, and a wraparound removable plate on the upper dental arch.

\section{FINAL CONSIDERATIONS}

Class II skeletal discrepancy, with an increased facial lower third, can be corrected by redirecting growth in young patients, or through orthognathic surgery, in adult patients. ${ }^{1}$ In both cases, it is possible to perform orthodontic camouflage when growth was not adequate or when the patient does not accept combined surgical-orthodontic treatment., ${ }^{2,3}$

In the present case, premolar extractions provided the space needed for the correction of upper incisor inclination, contraction of both arches and the mesial movement of lower molars. These changes favored the open bite closure in the posterior region, the correction of Class II relationship and overjet reduction. 

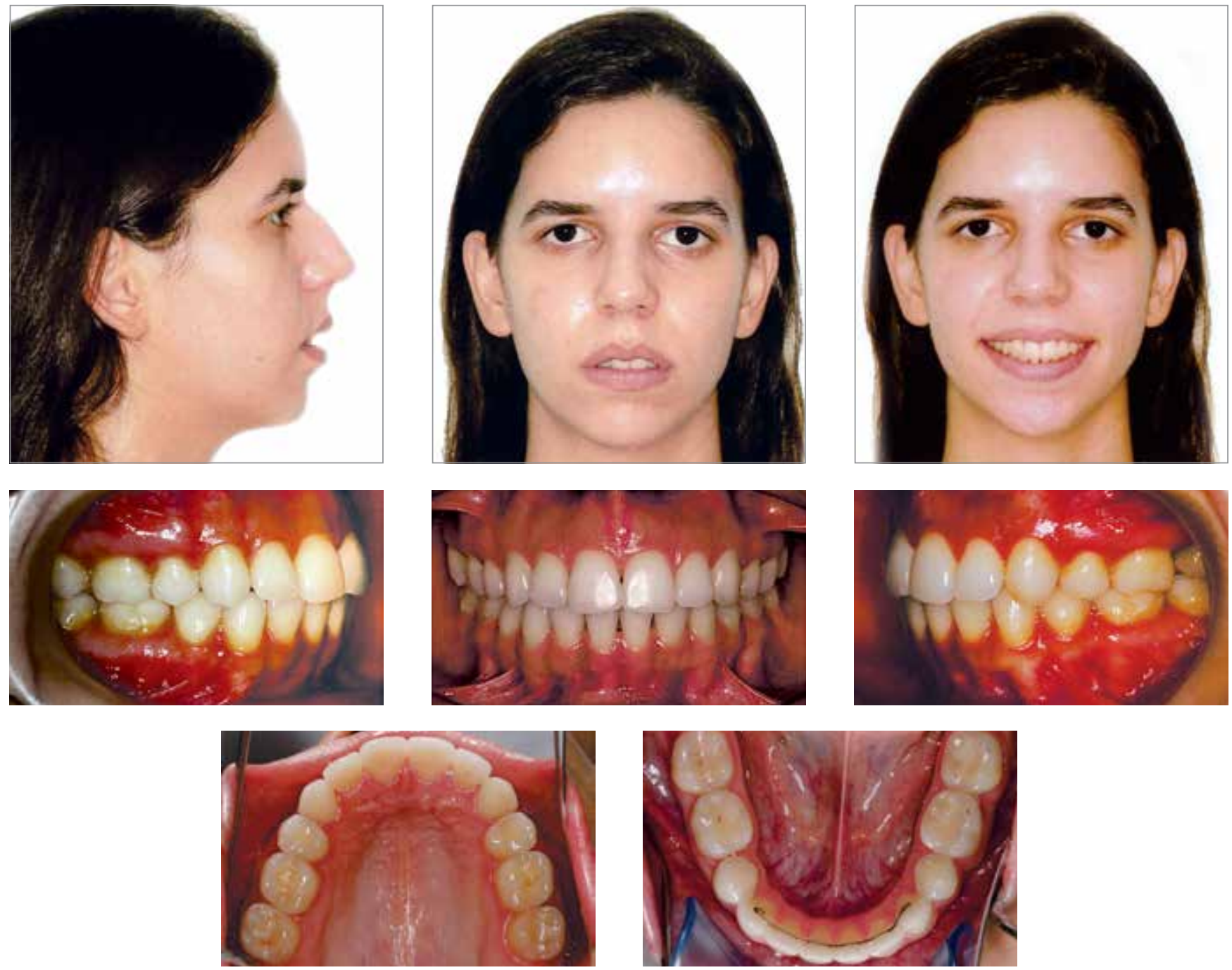

Figure 7 - Final facial and intraoral photographs.
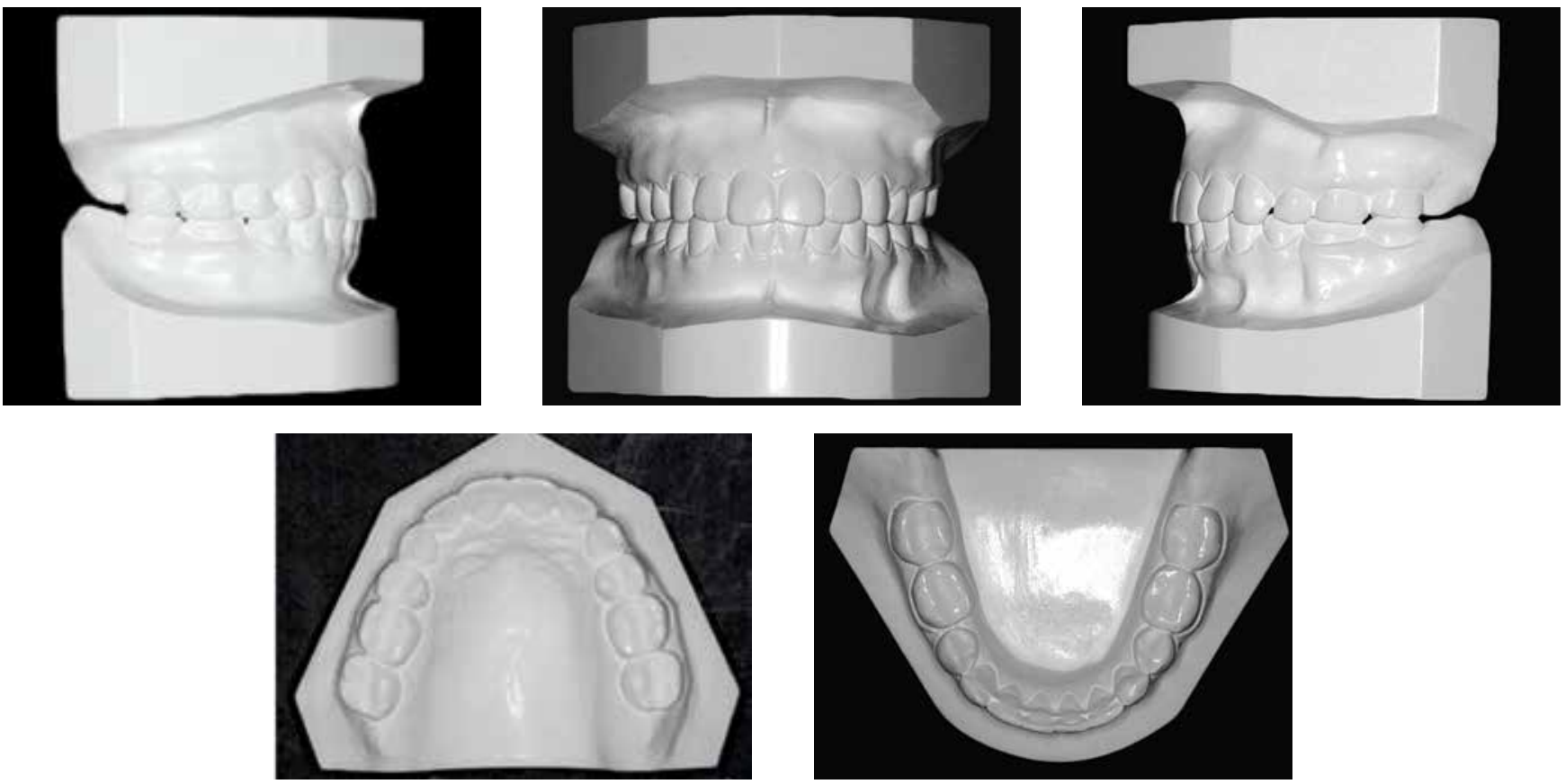

Figure 8 - Final dental casts. 


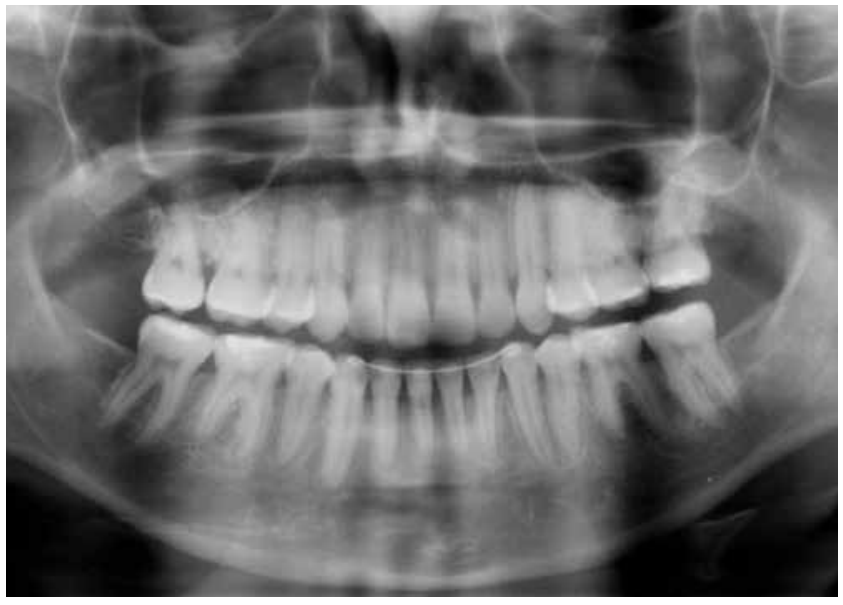

Figure 9 - Final panoramic radiograph.

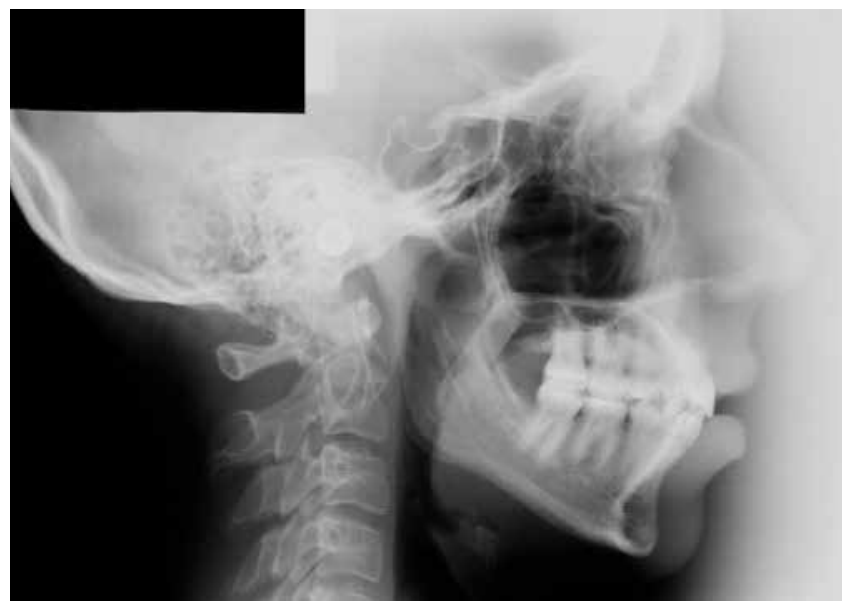

Figure 11 - Final lateral cephalometric radiograph.

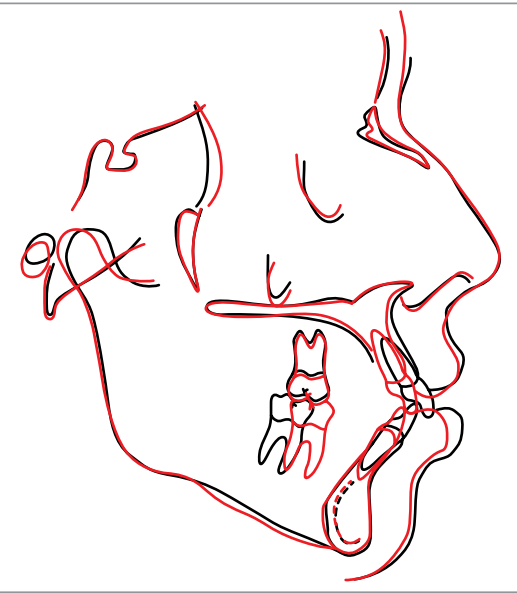

Figure 13 - Superimposition of initial (black) and final (red) cephalometric tracings, with register on SN.
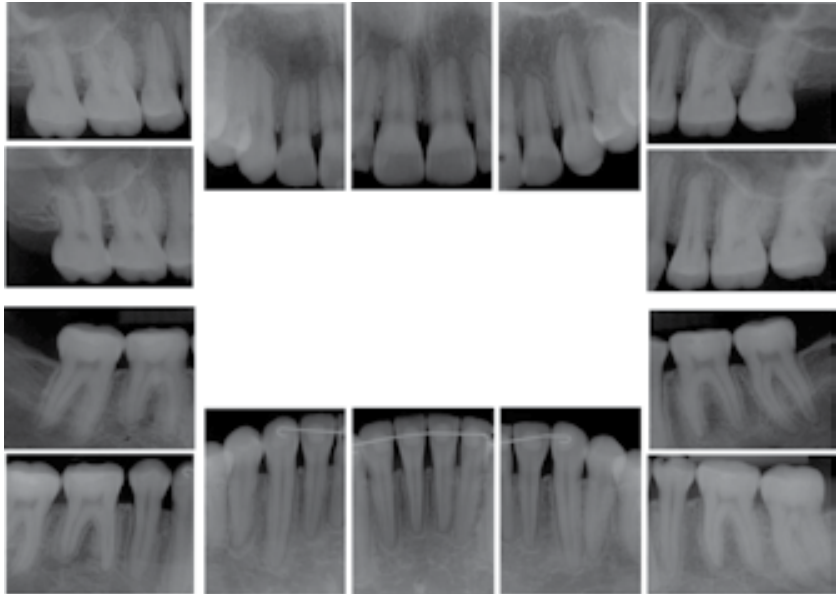

Figure 10 - Final periapical radiographs.

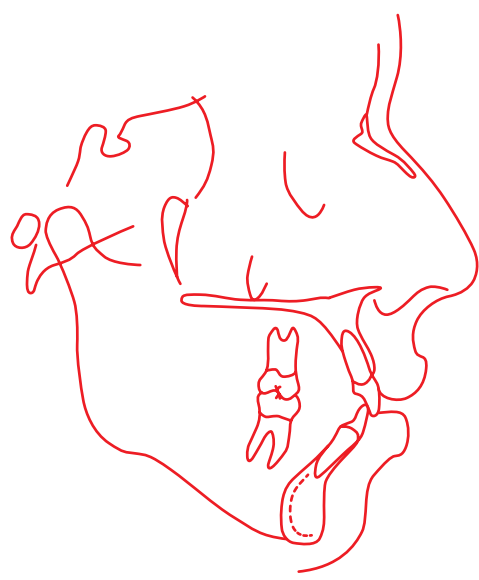

Figure 12 - Final cephalometric tracing

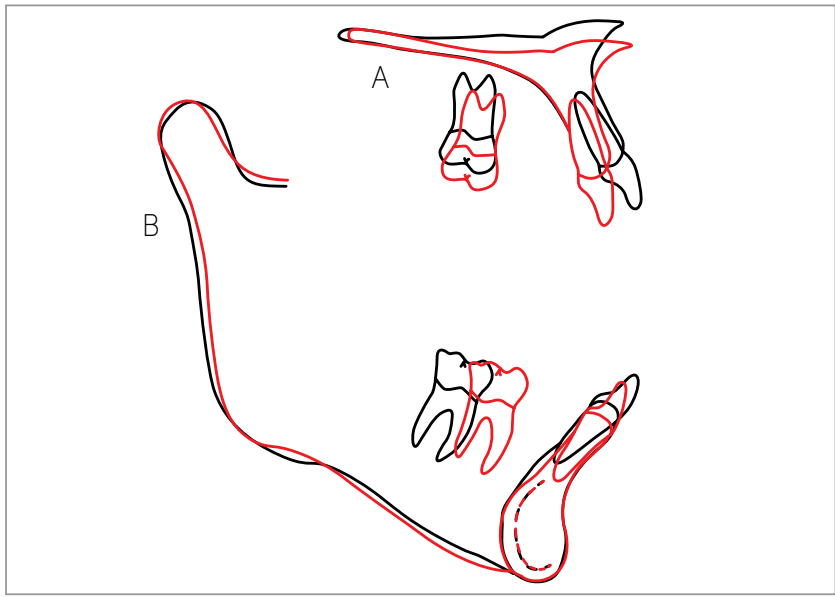

Figure 14 - Partial superimposition of maxilla (A) and mandible (B), evidencing tooth movement. 
Table 1 - Initial and final cephalometric values.

\begin{tabular}{|c|c|c|c|c|c|c|}
\hline & & & Normal & Initial & Final & A/B diff. \\
\hline \multirow{8}{*}{ Skeletal pattern } & SNA & (Steiner) & $82^{\circ}$ & $82^{\circ}$ & $81^{\circ}$ & 1 \\
\hline & SNB & (Steiner) & $80^{\circ}$ & $76^{\circ}$ & $77^{\circ}$ & 1 \\
\hline & ANB & (Steiner) & $2^{\circ}$ & $6^{\circ}$ & $4^{\circ}$ & 2 \\
\hline & Facial angle & (Downs) & $0^{\circ}$ & $10^{\circ}$ & $7^{\circ}$ & 3 \\
\hline & $Y$ axis & (Downs) & $59^{\circ}$ & $60^{\circ}$ & $63^{\circ}$ & 3 \\
\hline & Facial angle & (Downs) & $87^{\circ}$ & $87^{\circ}$ & $85^{\circ}$ & 2 \\
\hline & SN-GoGn & (Steiner) & $32^{\circ}$ & $36^{\circ}$ & $36^{\circ}$ & 0 \\
\hline & FMA & (Tweed) & $25^{\circ}$ & $27^{\circ}$ & $29^{\circ}$ & 2 \\
\hline \multirow{7}{*}{ Dental pattern } & IMPA & (Tweed) & $90^{\circ}$ & $105^{\circ}$ & $99^{\circ}$ & 6 \\
\hline & 1.NA (degrees) & (Steiner) & $22^{\circ}$ & $28^{\circ}$ & $20^{\circ}$ & 8 \\
\hline & 1-NA (mm) & (Steiner) & $4 \mathrm{~mm}$ & $10 \mathrm{~mm}$ & $8 \mathrm{~mm}$ & 2 \\
\hline & I.NB (degrees) & (Steiner) & $25^{\circ}$ & $36^{\circ}$ & $31^{\circ}$ & 5 \\
\hline & I-NB (mm) & (Steiner) & $4 \mathrm{~mm}$ & $14 \mathrm{~mm}$ & $11 \mathrm{~mm}$ & 3 \\
\hline & $\frac{1}{1}$ - Interincisal angle & (Downs) & $130^{\circ}$ & $108^{\circ}$ & $125^{\circ}$ & 17 \\
\hline & 1-APo (mm) & (Ricketts) & $1 \mathrm{~mm}$ & $9 \mathrm{~mm}$ & $7 \mathrm{~mm}$ & 2 \\
\hline \multirow{2}{*}{ Profile } & Upper lip - S line & (Steiner) & $0 \mathrm{~mm}$ & $2 \mathrm{~mm}$ & $1 \mathrm{~mm}$ & 1 \\
\hline & Lower lip - S line & (Steiner) & $0 \mathrm{~mm}$ & $7 \mathrm{~mm}$ & $4 \mathrm{~mm}$ & 3 \\
\hline
\end{tabular}

1. Tulloch JF, Lenz BE, Phillips C. Surgical versus orthodontic correction for Class II patients: Age and severity in treatment planning and treatment outcome. Semin Orthod. 1999;5(4):231-40

2. Bishara SE, Cummins DM, Jakobsen JR, Zaher AR. Dentofacial and soft tissue changes in Class II, division 1 cases treated with and without extractions. Am J Orthod Dentofacial Orthop. 1995:107(1):28-37.

3. Proffit WR, Fields HW, Sarver DM. Contemporary orthodontics. 4th ed. St. Louis: Mosby Elsevier; 2007. 